\title{
GEO- AND HYDRO-MECHANICAL EVALUATION OF SLOPE FAILURE INDUCED BY TORRENTIAL RAINS IN NORTHERN-KYUSHU AREA, JULY 2009
}

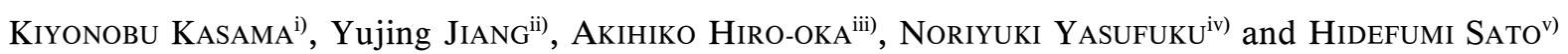

\begin{abstract}
Torrential rainfall in mid-July 2009 triggered numerous geodisasters such as slope failure and debris flow in Chugoku and Northern Kyushu areas of Japan. A number of slope failures and debris flows occurred in Yamaguchi and Fukuoka prefectures resulting in extensive damage to human life and infrastructure. One of the most serious geodisasters included a slope failure followed by debris flow at Sasaguri-machi and Fukuchi-machi, Fukuoka prefecture, Japan. This paper summarizes the results of geotechnical investigations on the geodisaster sites in Fukuoka prefecture. The geotechnical investigation included determining a series of grain size distributions, consistency limits and conducting direct box shear tests for collapsed soils collected at six disaster sites. The generation mechanisms of slope failure followed by debris flow were also investigated by analyzing the precipitation, topography, geology, and strength properties of the collapsed soils. Moreover, slope deformation and stability analyses were coupled with an unsaturatedsaturated seepage analysis to investigate the slope failure mechanism. The main findings from the study are summarized as: The physical properties, such as the grain size distribution, the plastic limit and liquid limit of collapsed soils, are summarized and compared with the results of other failure slopes in the literature. The collapsed soil was characterized as being a well grained soil (the uniformity coefficient $>50$ ) and highly weathered (the ignition loss $>5 \%$ ), however, with regard to the liquid limit and plastic index, there were no remarkable findings. The original shear strength for collapsed soils with natural water content is relatively large and slope failure doesn't occur because the cohesion in the shear strength is induced by a suction force between the soil particles under unsaturated condition. However, water seepage into the soil induces a drastic decrease in the shear strength, which is mainly caused by a decrease in cohesion (losing suction) resulting from soil saturation. In addition, the drained/undrained condition in the shear process is also sensitive to shear strength. For example, both water seepage and the shear process with constant volume cause an approximate 30\% reduction in shear strength for Fukuchi-machi and Sasaguri-machi soil samples. Therefore, the reduction of cohesive strength due to water seepage and the low permeability of the slope are the parameters which trigger geodisaster. Based on the results of slope deformation and a stability analyses which took the change in water pressure and cohesive strength into account, the geodisaster at Fukuchi-machi was simulated, it is reasonable to assume that the shallow failure near the top of slope occurred due to torrential precipitation of about 100 $\mathrm{mm}$ per hour which triggered a debris flow.
\end{abstract}

Key words: direct box shear test, rainfall, saturated-unsaturated seepage analysis, slope stability, stability analysis (IGC: D6/E6)

\section{INTRODUCTION}

Kyushu, the southernmost of Japan's four main islands, is known to be in a geographical and metrological position vulnerable to natural hazards such as typhoons and torrential rain due to rain front during rainy season. Table 1 summarizes the history of geodisasters caused by typhoons and torrential rain in Kyushu from 1969 to
2009: nineteen geodisasters occurred within those 40 years. That means that, statistaically, a geodisaster occurs in Kyushu about every two years, but, notably, there have been geodisasters every year since 2003. Table 2 shows the number of casualties resulting from geodisasters in Kyushu and Japan for the 1947-2005 period and from the 1996-2005 period, respectively. The total number of casualties in Kyushu alone and Japan as a

i) Associate Professor, Department of Civil and Structural Engineering, Kyushu University, Japan (kasama@civil.kyushu-u.ac.jp).

ii) Professor, Course of Civil and Environmental Engineering, Faculty of Engineering, Nagasaki University.

iii) Associate Professor, Department of Civil and Architectural Engineering, Kyushu Institute of Technology, Japan.

iv) Professor, Department of Civil and Structural Engineering, Kyushu University, Japan.

v) NihonChiken Co., Ltd., Fukuoka, Japan.

The manuscript for this paper was received for review on July 7, 2010; approved on February 8, 2011.

Written discussions on this paper should be submitted before May 1, 2012 to the Japanese Geotechnical Society, 4-38-2, Sengoku, Bunkyo-ku,

Tokyo 112-0011, Japan. Upon request the closing date may be extended one month. 
Table 1. The history of geodisaster in Kyushu Island from 1969 to 2005

\begin{tabular}{|c|c|c|c|c|}
\hline Year & Month & Place & Triggering factor & Death and missing persons \\
\hline 1969 & June & Kagashima-shi, Kagosima & Localized downpour & 52 \\
\hline 1971 & August & Kagashima-shi, Kagosima & Localized downpour & 47 \\
\hline 1972 & July & Asakusa, Kumamoto & Localized downpour & 115 \\
\hline 1976 & June & Kagashima-shi, Kagosima & Localized downpour & 32 \\
\hline 1982 & July & All prefectures, mainly Nagasaki & Localized downpour & 259 \\
\hline 1984 & June & Itsuki-machi, Kumamoto & Seasonal rain front & 16 \\
\hline 1986 & July & Kagashima-shi, Kagosima & Localized downpour & 18 \\
\hline 1990 & July & Ichinomiya-machi, Kumamoto & Seasonal rain front & 11 \\
\hline 1990 & September & Setouchi-machi, Kagoshima & Typhoon No. 19 & 11 \\
\hline 1993 & August & Kagashima-shi, Kagosima & Localized downpour & 47 \\
\hline 1997 & July & Izumi-shi, Kagoshima & Seasonal rain front & 21 \\
\hline 1999 & June & All prefectures, mainly Hiroshima & Seasonal rain front & 24 \\
\hline 2003 & July & Middle Kyushu & Seasonal rain front & 24 \\
\hline 2004 & September & Western Japan & Typhoon No. 21 & 17 \\
\hline 2005 & September & Yamaguchi and Western Kyushu & Typhoon No. 14 & 25 \\
\hline 2006 & July & Kagoshima & Seasonal rain front & 5 \\
\hline 2007 & July & Kumamoto and Kagoshima & Seasonal rain front & 2 \\
\hline 2008 & June & Kumamoto & Seasonal rain front & 1 \\
\hline 2009 & July & Northern Kyushu & Seasonal rain front & 34 \\
\hline
\end{tabular}

Table 2. The number of death and missing persons from 1947 to 2005

\begin{tabular}{c|c|c}
\hline & $1947-2005$ & $1996-2005$ \\
\hline Japan total & 4110 & 181 \\
\hline Kyushu area & 844 & 75 \\
\hline Percentage of Kyushu area & $21 \%$ & $41 \%$ \\
\hline
\end{tabular}

Table 3. Casualty and damage from the torrential rainfall

\begin{tabular}{|c|c|c|c|c|c|c|c|c|c|c|}
\hline \multirow{3}{*}{ Prefecture } & \multirow{3}{*}{ Debris flow } & \multirow{3}{*}{ Land slide } & \multirow{3}{*}{ Slope failure } & \multicolumn{2}{|c|}{ Personal injury } & \multicolumn{5}{|c|}{ Damage of house } \\
\hline & & & & \multirow{2}{*}{ Death } & \multirow{2}{*}{ Injured } & \multirow{2}{*}{$\begin{array}{l}\text { Completely } \\
\text { destroyed }\end{array}$} & \multirow{2}{*}{$\begin{array}{l}\text { Partially } \\
\text { destroyed }\end{array}$} & \multirow{2}{*}{ Damage } & \multicolumn{2}{|c|}{ Flood } \\
\hline & & & & & & & & & $\begin{array}{l}\text { Above } \\
\text { floor level }\end{array}$ & $\begin{array}{c}\text { Under } \\
\text { floor level }\end{array}$ \\
\hline Yamaguchi & 65 & 2 & 125 & 20 & 35 & 33 & 77 & 51 & 695 & 3864 \\
\hline Fukuoka & 4 & 2 & 8 & 10 & 18 & 13 & 11 & 70 & 1318 & 4126 \\
\hline Saga & 2 & & 5 & 1 & & & & 14 & 81 & 1065 \\
\hline Nagasaki & & 1 & 26 & 1 & & & & 5 & 1 & 35 \\
\hline Kumamoto & & & 2 & & & 1 & & & 1 & 18 \\
\hline Oita & & & 7 & & & & & 1 & 1 & 1 \\
\hline
\end{tabular}

whole has decreased remarkably; however, the high percentage of casualties in Kyushu since 1996 indicates the high frequency of geodisasters in the Kyushu area. Therefore, disaster prevention against geodisaster due to typhoon and torrential rain is one of the primary geotechnical concerns in the Kyushu area of Japan.

An activated seasonal rain front in northern Kyushu caused torrential rainfall around Chugoku (the western 
area of Honshu, the main sland) and in northern Kyushu in mid-July, 2009. As a result, the total precipitation during this period at several local meteorological observatories was more than $500 \mathrm{~mm}$, which was above the previous maximum precipitation record. Torrential rainfall triggered numerous geodisasters such as slope failure and debris flow in the Yamaguchi and Fukuoka prefectures, causing extensive damage to human life and infrastructure. Table 3 gives the casualties and damage caused by torrential rains in the Northern-Kyushu area, July 2009 and summarizes the geodisasters into the following categories: debris flow, landslide and slope failure. The geodisasters included 65 debris flows, 2 landslides and 125 slope failures in Yamaguchi prefecture; 6 debris flows in Fukuoka and Saga prefectures; and 3 landslides in the Fukuoka and Nagasaki prefectures. There were 48 slope failures in the Kyushu area, with 26 of them concentrated in Nagasaki prefecture. At Onojo-shi, Fukuoka prefecture, there was a $35 \mathrm{~m}$ long debris flow, where the collapsed soil which triggered the debris flow consisted of weathered granite. At national roads No. 201 and No. 385 in Fukuoka prefecture, there were slope failures resulting in blocked traffic roadways. On the national road No. 200 in Fukuoka prefecture, the traffic roadway was eroded by the overflow of a river. One of the most serious geodisasters in Fukuoka prefecture included a large scale slope failure followed by debris flows in Sasaguri-machi and Fukuchi-machi, which resulted in three deaths. The feature of geodisasters at Fukuchimachi and Sasaguri-machi are explained later. The Kyushu branch of the Japanese Geotechnical Society dispatched experts, among which there were academic researchers, governmental officers and geotechnical consultants, to investigate the site for the purpose of clarifying the generation mechanism of the geodisaster due to rainfall and to propose effective countermeasures against the reoccurrance of such a geodisaster.

In order to clarify all the factors which led to the geodisaster due to rainfall in detail, this paper summarizes the results of grain size distribution tests, consistency limit tests and box shear tests for collapsed soils collected at six disaster sites in Northern Kyushu and compares the results with the results of other failure slopes in the literature. The generation mechanisms of slope failure followed by debris flow were also investigated by analyzing the precipitation, topography, geology, and the strength properties of the collapsed soils. Moreover, a slope deformation and stability analyses was coupled with an unsaturated-saturated seepage analysis to investigate the slope failure mechanism due to rainfall.

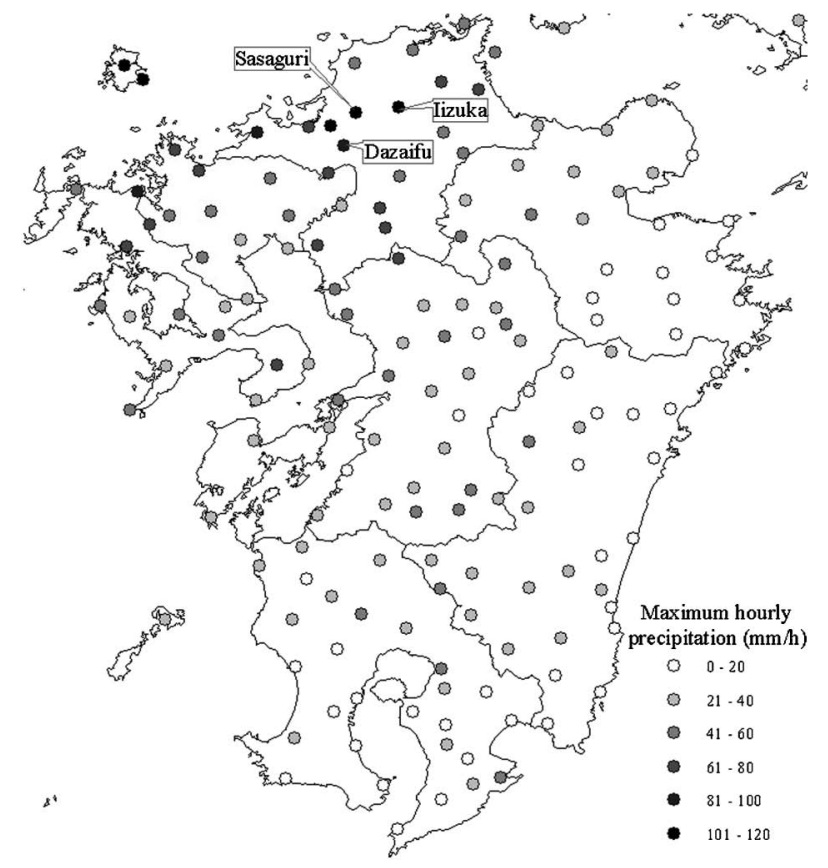

Fig. 1. Maximum hourly precipitation in Kyushu Area from 24th to 26th July, 2009

\section{METEOROLOGICAL DATA IN NORTHERN-KYUSHU AREA, JULY 2009}

Figure 1 shows the maximum hourly precipitation from 24th to 26th July 2009 recorded by the Japan Meteorological Agency at meteorological observatories in the Kyushu and Chugoku areas. Table 4 summarizes the location of the meteorological observatories in the Chugoku and Kyushu areas in order of the maximum hourly precipitation. The hourly precipitation at several meteorological observatories in Fukuoka and Nagasaki prefectures reached more than $100.0 \mathrm{~mm} / \mathrm{h}$, clearly indicating torrential rainfall in Northern-Kyushu. Figure 2 shows the total precipitation from 24th to 26th July 2009 in Northern-Kyushu area. Table 5 summarizes the location of meteorological observatories according to the total precipitation. The precipitations at Dazaifu (618 $\mathrm{mm})$, Iizuka $(568 \mathrm{~mm})$ and Kusenbuyama $(562 \mathrm{~mm})$ in Fukuoka prefecture reached more than $550 \mathrm{~mm}$, which corresponds to one third of the annual total precipitation in this area.

In order to examine the meteorological characteristic of the Northern-Kyushu area, the hourly and accumulated precipitations from 24th to 26th July 2009 recorded at Dazaifu, Iizuka and Sasaguri observatories are shown in Fig. 3. It is noted that the Dazaifu, Iizuka and Sasaguri observatories are listed in Tables 4 and 5 and the time zone, when geodisasters occurred near the observatory, are shown in hatches in the figure. There are two apparent peaks in the hourly precipitation on the 24th and 26th July, respectively, at three observatories, with the first peak relatively larger than the second one. Because of the large amount of precipitation, as shown in Fig. 3, a number of geodisasters occurred in Iizuka on the $24 \mathrm{th}$, in 
Table 4. The ranking of hourly precipitation

\begin{tabular}{|c|c|c|c|c|c|c|}
\hline \multirow{2}{*}{ Rank } & \multirow{2}{*}{ Prefecture } & \multirow{2}{*}{ Municipality } & \multirow{2}{*}{ The name of observatory } & \multicolumn{3}{|c|}{ Precipitation } \\
\hline & & & & $(\mathrm{mm})$ & Date & Time \\
\hline 1 & Fukuoka & Fukuoka-city, Hakata-ward & Hakata & 116.0 & $7 / 24$ & $19: 25$ \\
\hline 2 & Nagasaki & Iki-shi & Ishida & 111.0 & $7 / 24$ & $16: 55$ \\
\hline 3 & Nagasaki & Iki-shi & Ashibe & 103.0 & $7 / 24$ & $19: 32$ \\
\hline 4 & Fukuoka & Iizuka-shi & Iizuka & 101.0 & $7 / 24$ & $19: 52$ \\
\hline 5 & Fukuoka & Kasuya-gun, Sasaguri-machi & Sasaguri & 100.5 & $7 / 24$ & $19: 30$ \\
\hline 6 & Fukuoka & Maebaru-shi & Maebaru & 92.0 & $7 / 24$ & $19: 20$ \\
\hline 7 & Fukuoka & Dazaifu-shi & Dazaifu & 84.0 & $7 / 24$ & $20: 04$ \\
\hline 8 & Nagasaki & Matsuura-shi & Matsuura & 81.0 & $7 / 26$ & $9: 21$ \\
\hline 9 & Fukuoka & Chikushi-gun, Nakagawa-machi & Kusenbuyama & 80.0 & $7 / 26$ & $11: 18$ \\
\hline 10 & Fukuoka & Kitakyushu-shi & Kagumeyoshi & 79.5 & $7 / 24$ & $18: 38$ \\
\hline 10 & Nagasaki & Sasebo-shi & Sasebo & 79.5 & $7 / 25$ & $1: 49$ \\
\hline
\end{tabular}

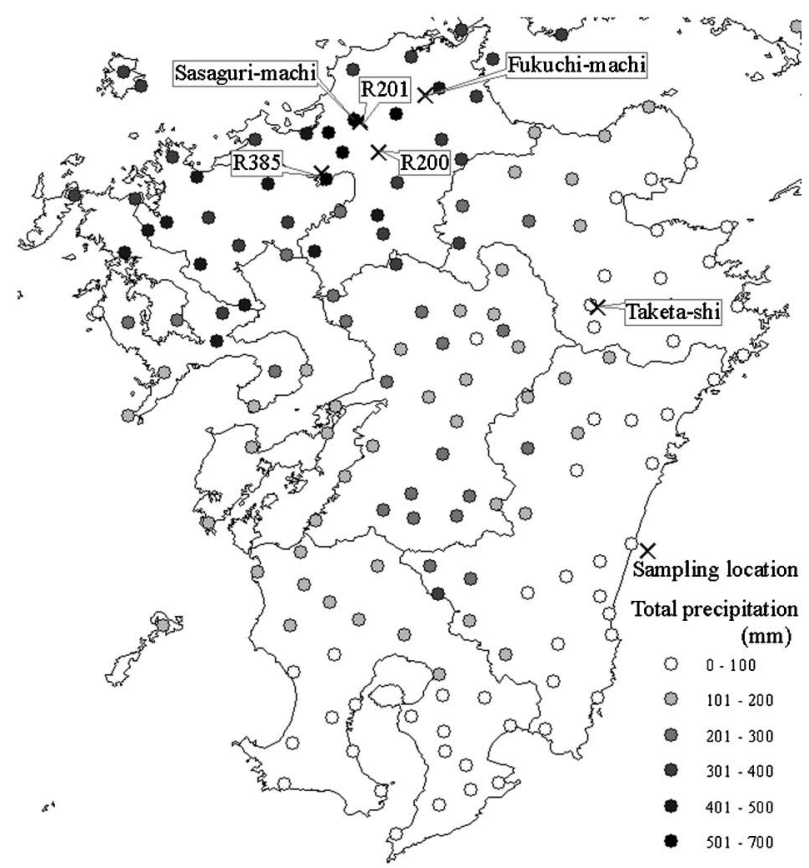

Fig. 2. Total precipitation in Kyushu Area from 24th to 26th July, 2009

Sasaguri early in the morning on the 25th, in the Dazaifu area on the 26th, respectively. Therefore, the main factor the geodisaster is considered to be torrential rainfall.

\section{TYPICAL GEODISASTER IN NORTHERN-KYUSHU AREA}

The characteristics of a typical geodisaster, such as slope failure and debris flow induced by the torrential rainfall, are briefly summarized in this section. The slope failures followed by debris flow in Sasaguri-machi, Kasuya-gun, in Fukuoka prefecture are shown in Fig. 4. Three slope failures about $20 \mathrm{~m}$ in width and $3-5 \mathrm{~m}$ in depth occurred on the right side along a similar tributary and the collapsed soil mass temporally blocked rainfall. Then, the collapsed soil mass with a large amount of water became a debris flow $100 \mathrm{~m}$ in length, and destroyed the homes in its path. Figure 4(c) shows a sectional view of slope failure B. The original slope angle was about 33 degrees, and the surface layer of the slope consisted of a highly weathered weak gravelly clay with a low water content. It is estimated that the collapsed soil mass was $20 \mathrm{~m}$ in width, $5 \mathrm{~m}$ in depth, $50 \mathrm{~m}$ in length and had a total volume of $2400 \mathrm{~m}^{3}$, which is larger than the other two slope failures.

A large debris flow in Fukuchi-machi, in Tagawa-gun, Fukuoka prefecture is shown in Fig. 5. The original slope angle was 24-32 degree. Although the slope of the bed rock was very stiff, the slope surface was highly weathered to around $3 \mathrm{~m}$ in depth, which implies it had high failure potential. The debris flow was $50 \mathrm{~m}$ in width, $3 \mathrm{~m}$ in depth and $400 \mathrm{~m}$ in length. The debris flow descended about $160 \mathrm{~m}$ in elevation and the head of debris flow crushed houses in its path. The debris flow covered the original slope surface with a layer about $3 \mathrm{~m}$ thick.

In the case of both the geodisasters mentioned above, the original slope angle was less than 40 degrees, which is considered to be stable under normal conditions, and a large scale debris flow was induced prior to slope failure.

\section{GEOTECHNICAL PROPERTY OF COLLAPSED SOIL}

\section{Physical Property}

Soils were sampled from the collapsed soils of the slope failure and the debris flow at Fukuchi-machi, Sasagurimachi in Fukuoka prefecture and in Taketa-city in Oita prefecture. In addition, soil samples were taken from the collapsed soils of the slope failure along national roads No. 200, No. 201 and No. 385 in Fukuoka prefecture. 
Table 5. The ranking of total precipitation in Kyushu are

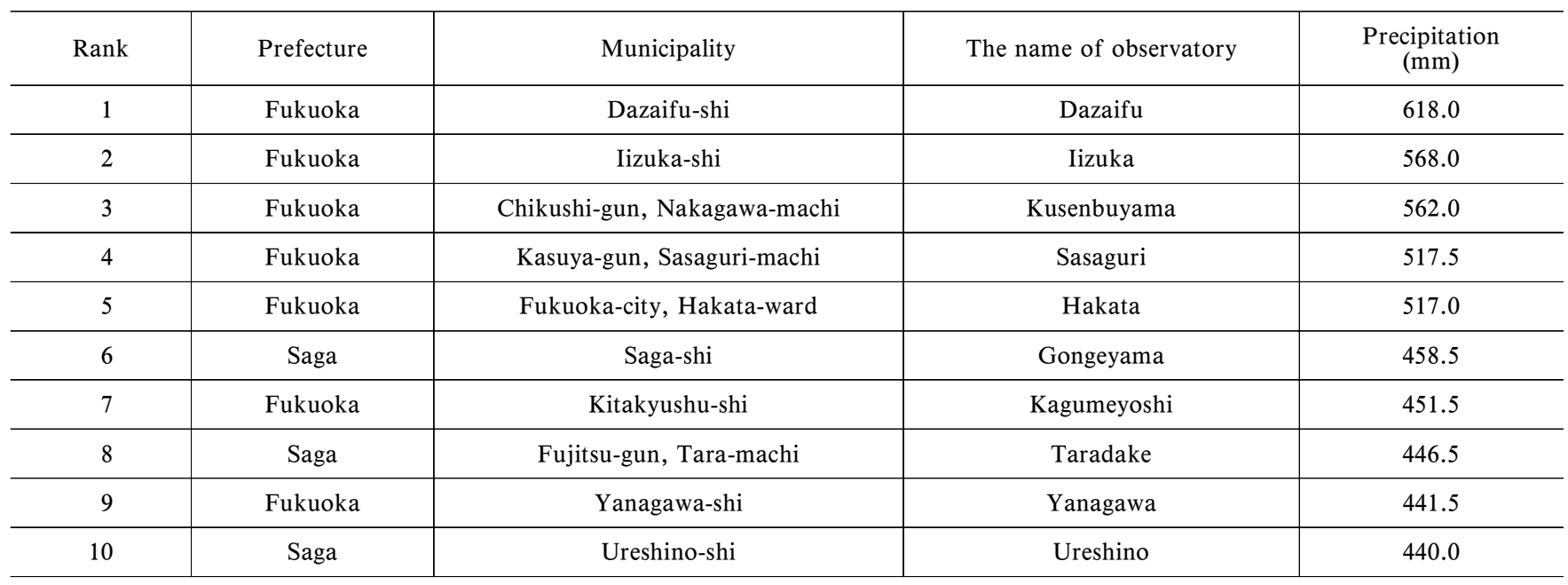

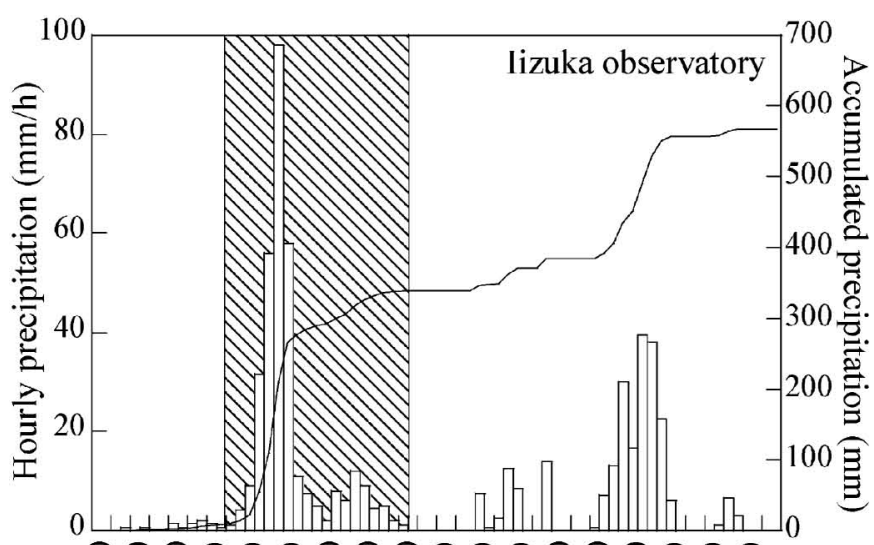

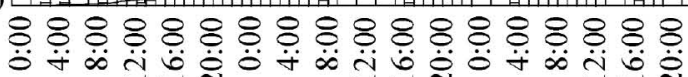

24th 25th 26th a) Iizuka observatory

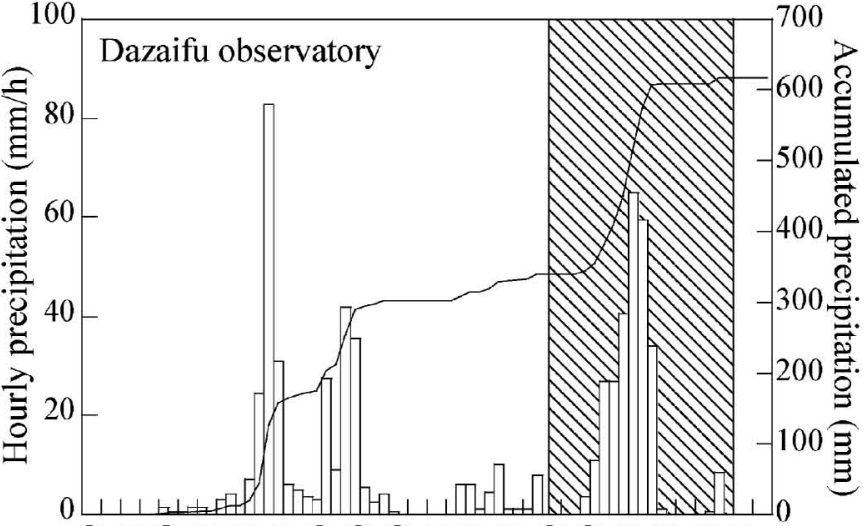

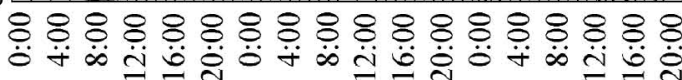

24th 25th

26th

b) Dazaifu Observatory

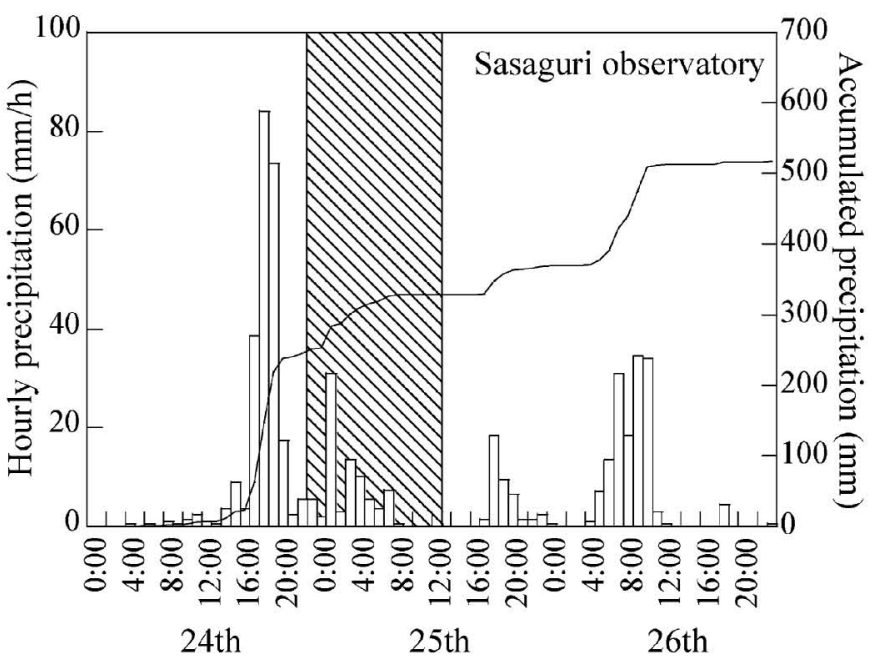

c) Sasaguri observatory

Fig. 3. Time history of precipitation from 24th to 26th July 2009 in Northern-Kyushu area 

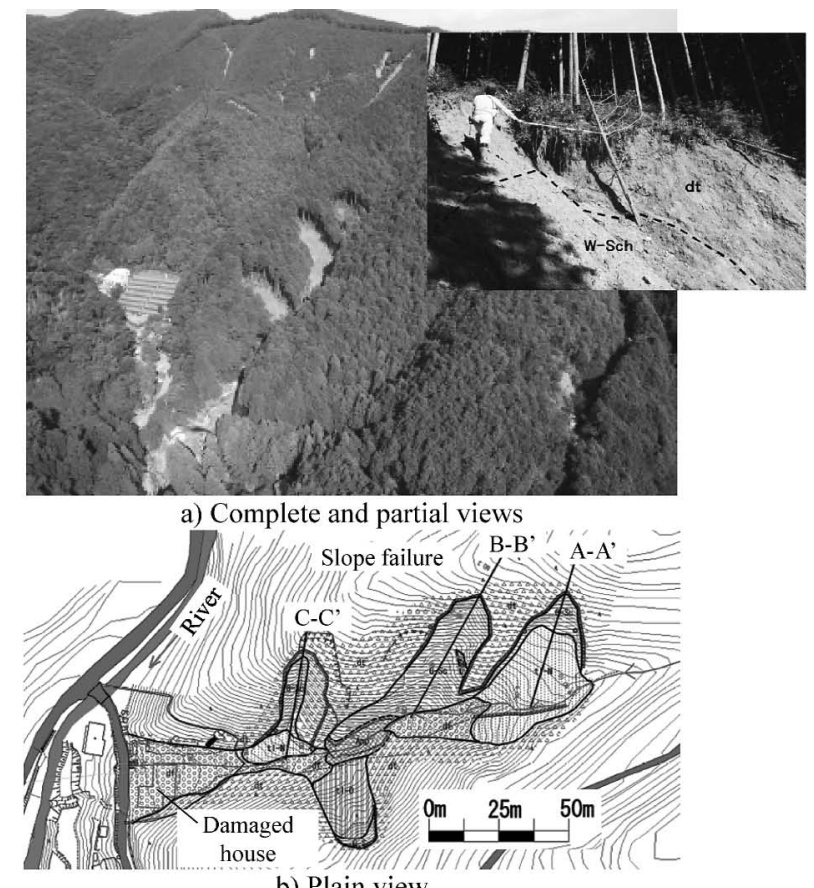

b) Plain view

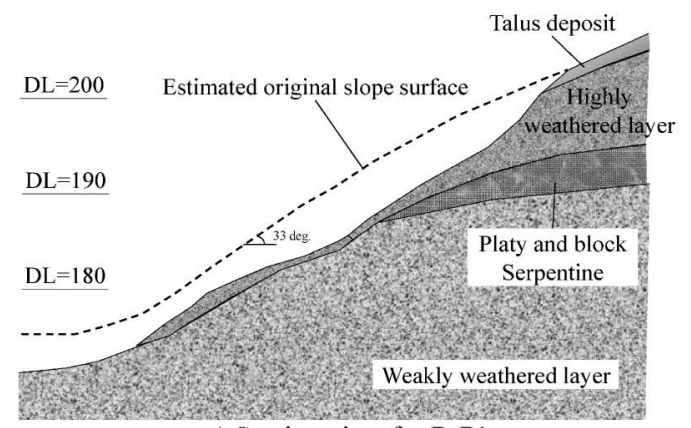

c) Section view for B-B'

Fig. 4. Geodisaster occurred at Sasaguri-machi, Fukuoka

The locations of the six sampling sites are shown in Fig. 2: the six sites will be referred to as "Fukuchi-machi", "Sasaguri-machi",, “Takeda-shi”, “R200”, “R201”, and "R385" throughout the remainder of this paper.

The physical properties of the soil samples are summarized in Table 6 and the grain size distribution curves are shown in Fig. 6. All the soil samples taken from six geodisaster sites were considered well graded because they consisted of gravel, sand silt and clay uniformly, and, notably, had a uniformity coefficient of over 50. All the soil samples except for that taken from Takeda-shi, were categorized as sandy gravel or gravely sand based on the JSG standards: a gravelly sand has a gravel and sand content of over $50 \%$. The Takeda-shi sample was categorized as clay since the content of silt and clay was over $50 \%$.

Table 7 summarizes the specific gravity, the natural water content, the consistency limits and the ignition loss. The ignition loss of more than 5\% indicates that the collapsed soils were highly weathered. Figure 7 shows the relationships between the liquid limit and the plastic index. The test results of the soil samples taken from prior geodisasters in the Kyushu area (Kyushu Branch of JGS, 2003, 2009; Kasama et al., 2006; Yahiro et al., 2006,

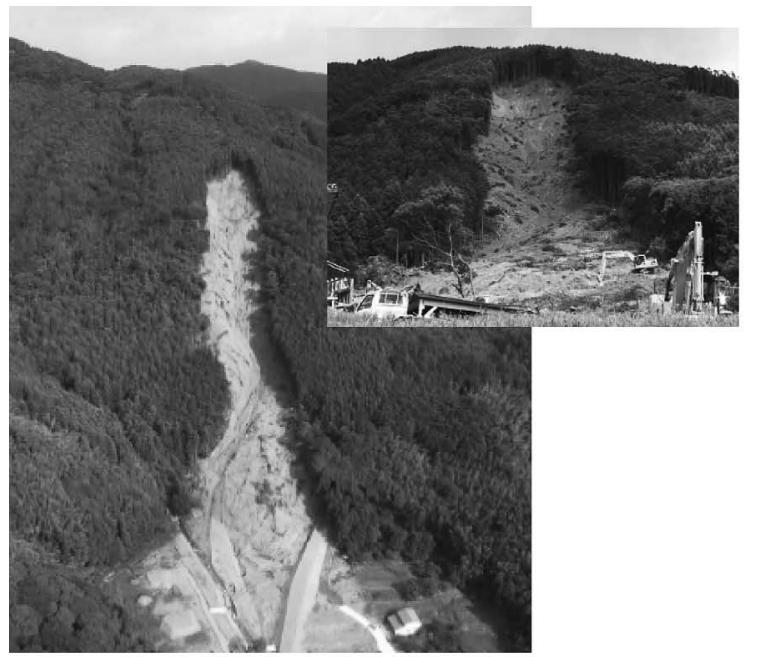

a) Complete and partial views

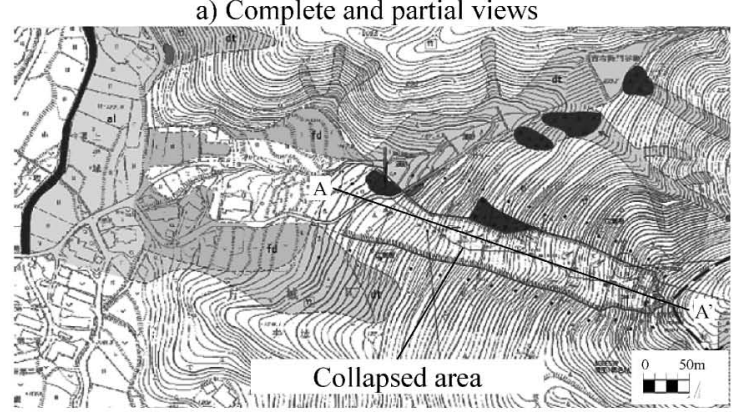

b) Plain view

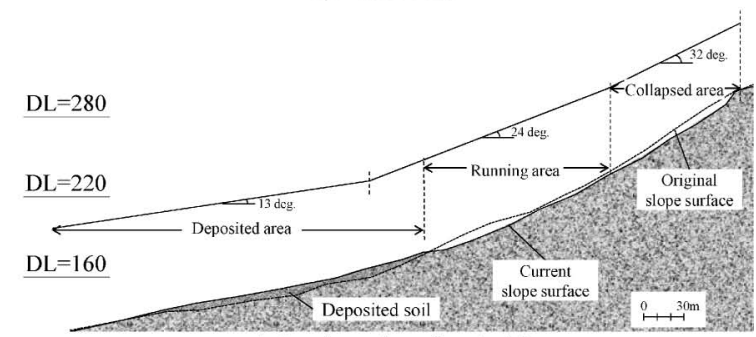

c) Section view for $A-A^{\prime}$

Fig. 5. Geodisaster occurred at Fukuchi-machi, Fukuoka

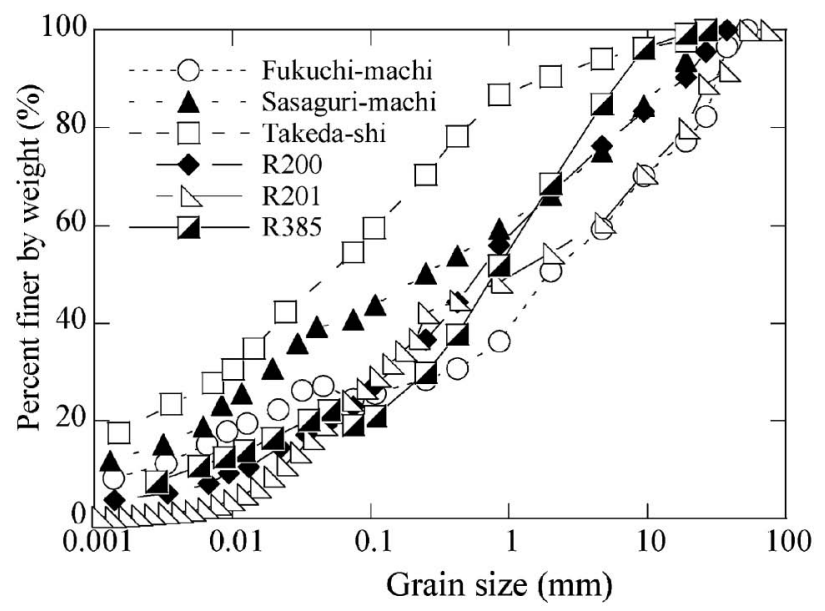

Fig. 6. Grain size distribution 
Table 6. Characteristics of soil grain size of collapsed soils

\begin{tabular}{|c|c|c|c|c|c|c|c|c|}
\hline \multirow{2}{*}{ Soil sample } & \multirow{2}{*}{$\begin{array}{c}\text { Sampling } \\
\text { No. }\end{array}$} & \multicolumn{4}{|c|}{ Grain content (\%) } & \multirow{2}{*}{$\begin{array}{c}\text { Uniformity } \\
\text { coefficient } \\
\text { Uc }\end{array}$} & \multirow{2}{*}{$\begin{array}{c}\text { Curvature } \\
\text { coefficient } \\
\text { U'c }\end{array}$} & \multirow{2}{*}{$\begin{array}{c}\text { JGS } \\
\text { standard }\end{array}$} \\
\hline & & Gravel & Sand & Silt & Clay & & & \\
\hline \multirow{5}{*}{ Fukuchi-machi } & 1 & 41 & 22 & 26 & 11 & 491 & 0.107 & GFS \\
\hline & 2 & 52 & 15 & 24 & 9 & 935 & 0.087 & GF-S \\
\hline & 3 & 44 & 14 & 29 & 12 & 1165 & 0.029 & GF-S \\
\hline & 5 & 45 & 33 & 9 & 13 & 857 & 24.00 & GFS \\
\hline & 6 & 54 & 20 & 10 & 17 & 9000 & 6.400 & GFS \\
\hline Sasaguri-machi & 1 & 34 & 26 & 22 & 19 & 1000 & 0.320 & GFS \\
\hline Taketa-shi & 1 & 10 & 36 & 29 & 25 & - & - & $\mathrm{CL}$ \\
\hline \multirow{3}{*}{ R200 } & 1 & 15 & 55 & 20 & 11 & 62 & 1.885 & SFG \\
\hline & 2 & 61 & 22 & 13 & 4 & 550 & 0.727 & GFS \\
\hline & 3 & 25 & 54 & 14 & 7 & 50 & 2.000 & SFG \\
\hline R201 & 1 & 46 & 30 & 23 & 2 & 200 & 0.109 & GFS \\
\hline \multirow{3}{*}{ R385 } & 1 & 29 & 53 & 4 & 15 & 1000 & 3.600 & $\mathrm{SFG}$ \\
\hline & 2 & 27 & 61 & 1 & 11 & 467 & 5.357 & SG-F \\
\hline & 3 & 38 & 34 & 18 & 9 & 257 & 1.341 & GFS \\
\hline
\end{tabular}

GFS: fine and sandy gravels, GF-S: fine gravel with slight sand, SFG: fine and gravelly sand, CL: clay (low liquid limit), SG-F: gravelly sand with slight fine

Table 7. Physical properties of collapsed soils

\begin{tabular}{|c|c|c|c|c|c|c|c|}
\hline \multirow{2}{*}{ Soil sample } & \multirow{2}{*}{$\begin{array}{c}\text { Sampling } \\
\text { No. }\end{array}$} & \multirow{2}{*}{$\begin{array}{l}\text { Density } \\
\left(\mathrm{g} / \mathrm{cm}^{3}\right)\end{array}$} & \multirow{2}{*}{$\begin{array}{c}\text { Water } \\
\text { content } \\
(\%)\end{array}$} & \multicolumn{3}{|c|}{ Consistency limits } & \multirow{2}{*}{$\begin{array}{c}\text { Ignition } \\
\text { loss } \\
(\%)\end{array}$} \\
\hline & & & & $w_{\mathrm{p}}(\%)$ & $w_{\mathrm{L}}(\%)$ & $I_{\mathrm{P}}$ & \\
\hline \multirow{6}{*}{ Fukuchi-machi } & 1 & 2.819 & 30.3 & 23.7 & 47.5 & 23.8 & - \\
\hline & 2 & 2.816 & 36.2 & 24.1 & 49.3 & 25.2 & - \\
\hline & 3 & 2.813 & 24.8 & 26.8 & 50.1 & 23.3 & - \\
\hline & 4 & 2.878 & 40.3 & 36.9 & 49.6 & 12.8 & 9.5 \\
\hline & 5 & 2.932 & 30.0 & 33.3 & 55.1 & 21.8 & 9.9 \\
\hline & 6 & 2.870 & 21.8 & 24.6 & 40.9 & 16.3 & 6.7 \\
\hline Sasaguri-machi & 1 & 2.820 & 34.4 & 39.2 & 67.5 & 28.3 & 9.1 \\
\hline Takeda-shi & 1 & 2.662 & - & 62.7 & 29.0 & 33.7 & - \\
\hline \multirow{3}{*}{ R200 } & 1 & 2.682 & 10.5 & 38.1 & 48.7 & 10.6 & 8.7 \\
\hline & 2 & 2.704 & 6.1 & 34.0 & 36.4 & 2.4 & 9.9 \\
\hline & 3 & 2.738 & 2.6 & 28.2 & 35.1 & 6.9 & 3.7 \\
\hline R201 & 1 & 2.826 & 16.6 & 18.6 & 36.6 & 18.0 & - \\
\hline \multirow{3}{*}{ R385 } & 1 & 2.674 & 20.8 & 39.2 & 56.8 & 17.6 & 6.2 \\
\hline & 2 & 2.592 & 22.6 & 37.7 & 46.0 & 8.3 & 6.9 \\
\hline & 3 & 2.613 & 21.1 & 34.5 & 48.5 & 14.0 & 7.1 \\
\hline
\end{tabular}

2007) are also shown as solid squares in the figure. The large scatter of test results around the intersection of lines $A$ and $B$ appears to indicate that neither the liquid limit or plasticity index were features of the collapsed soils.

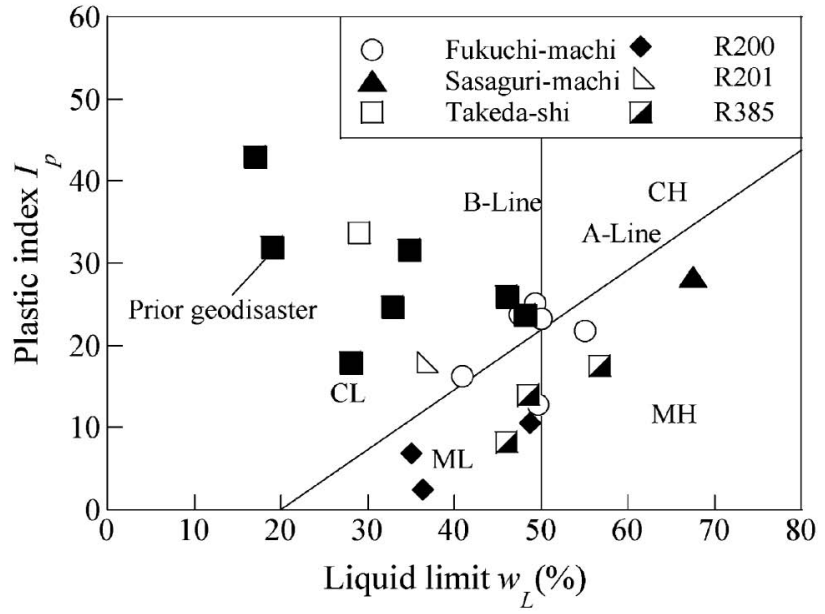

Fig. 7. The relationship between plastic index and liquid limit

\section{Shear Strength Property}

In order to examine the strength properties of the collapsed soils in normal conditions, a series of consolidated constant pressure direct box shear tests was carried out for Fukuchi-machi, Sasaguri-machi, Takeda-shi, R200 and R385 samples sieved under $2 \mathrm{~mm}$. The specimen size was $60 \mathrm{~mm}$ in diameter and $20 \mathrm{~mm}$ in height. The soil specimens were prepared using soil with natural water content by gently spooning it into the mold $(60 \mathrm{~mm}$ in diameter and $20 \mathrm{~mm}$ in height) in three layers, and then tamping it to control the density of specimen. It is noted that the soil specimen was in an initially unsaturated con- 


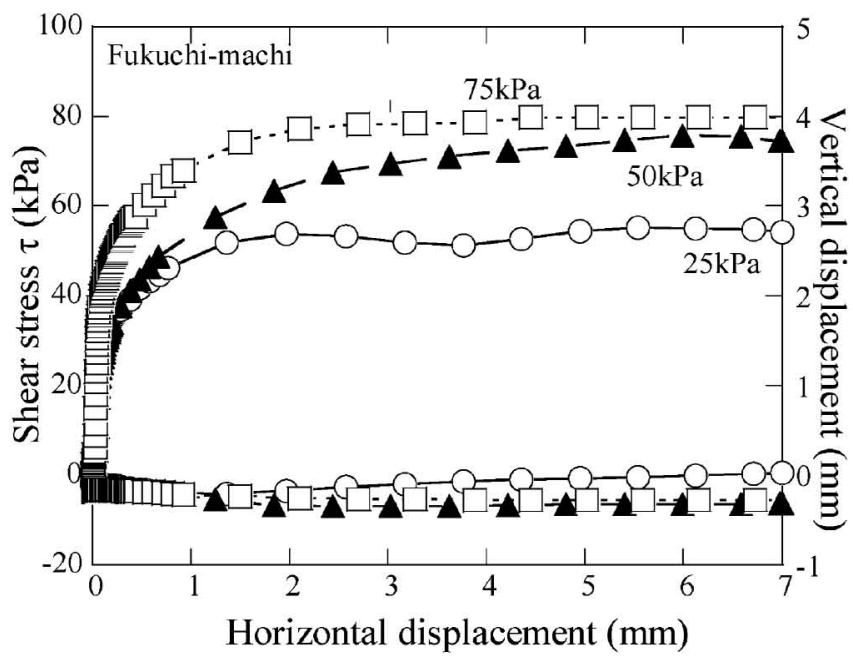

a) Fukuchi-machi

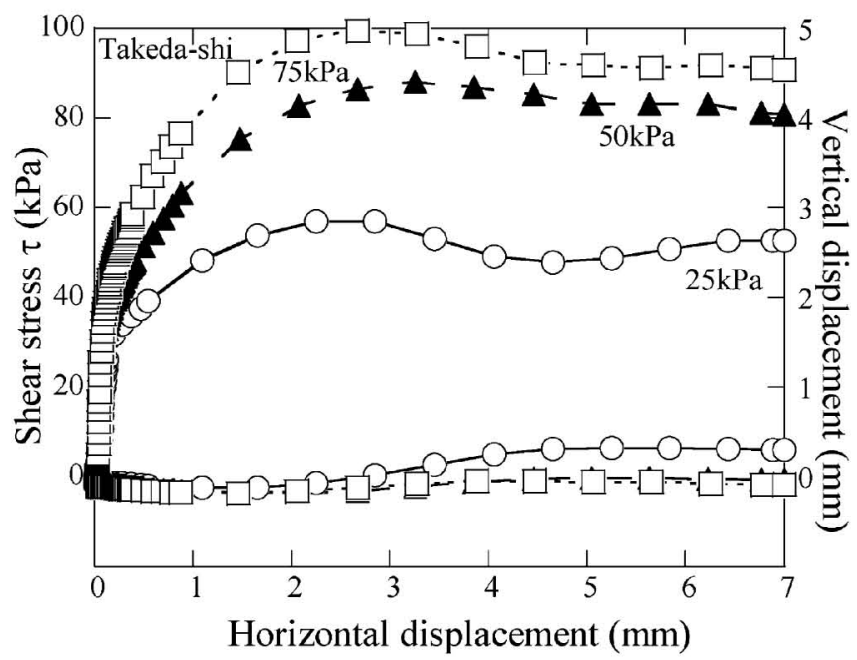

c) Takeda-shi

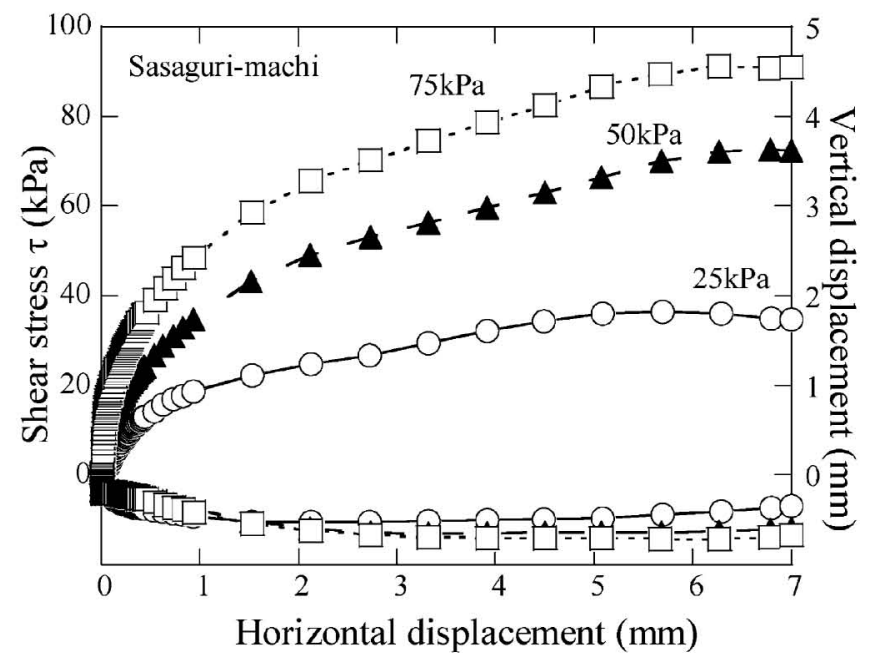

b) Sasaguri-machi

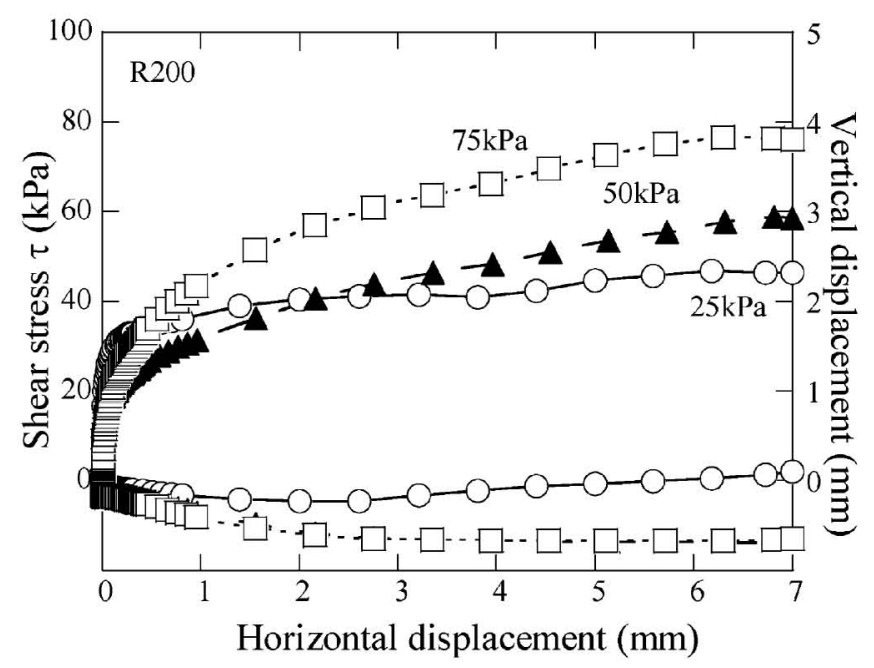

d) R200

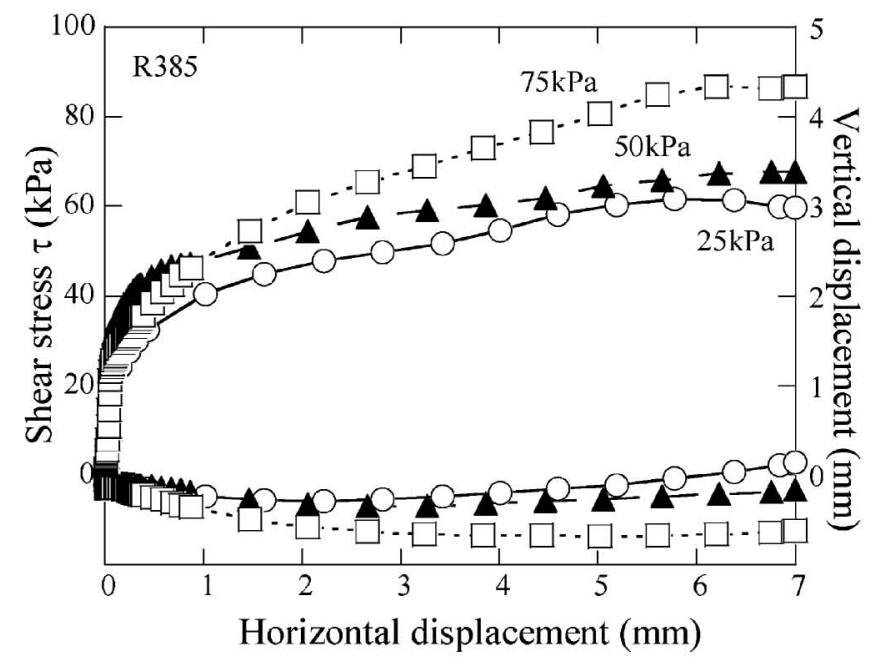

e) R385

Fig. 8. Shear stress and vertical displacement against horizontal displacement under constant vertical stress 
dition. To keep the specimens in their unsaturated condition, the specimens were consolidated with constant vertical pressures of $25 \mathrm{kPa}, 50 \mathrm{kPa}$ and $75 \mathrm{kPa}$ and then sheared with a drained condition of up to $7 \mathrm{~mm}$ at a shear speed of $0.1 \mathrm{~mm} / \mathrm{min}$ according to the JGS standard.

Figure 8 shows the shear stress and the vertical displacement against horizontal displacement. It can be seen that all soil samples except for the Takeda-city sample showed a monotonous increase in the stress-displacement behavior with volumetric compression similar to normally consolidated clay and loose sand. Taketa-shi sample shows that there was a peak in shear stress around the horizontal displacement of 2-3 mm, which was similar to stress-strain behavior of overconsolidated clay. The failure criteria are shown in Fig. 9. As all soil samples were in the unsaturated condition, it can be determined that there is was an intercept in the failure criteria derived from the suction force between soil particles. The friction angles of Sasaguri-machi, Takeda-city and R385 samples

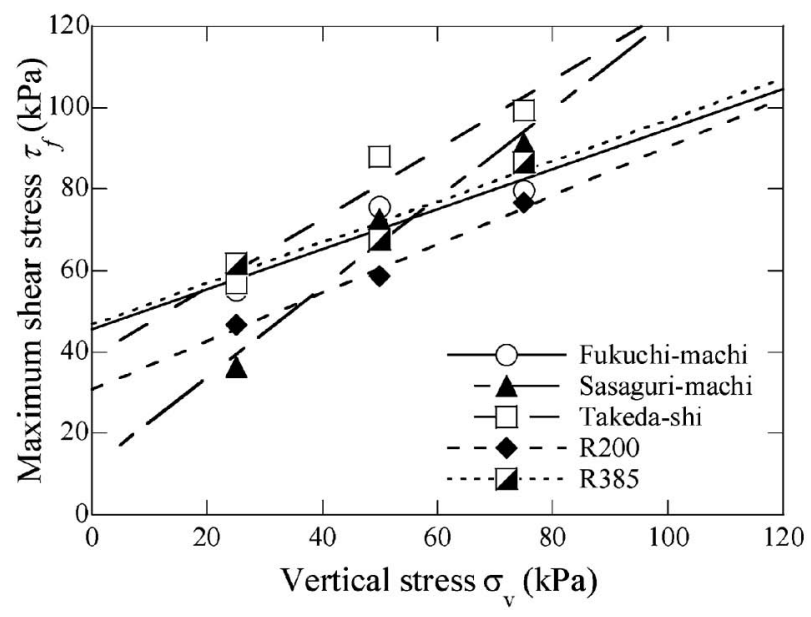

Fig. 9. Failure criteria of collapsed soil

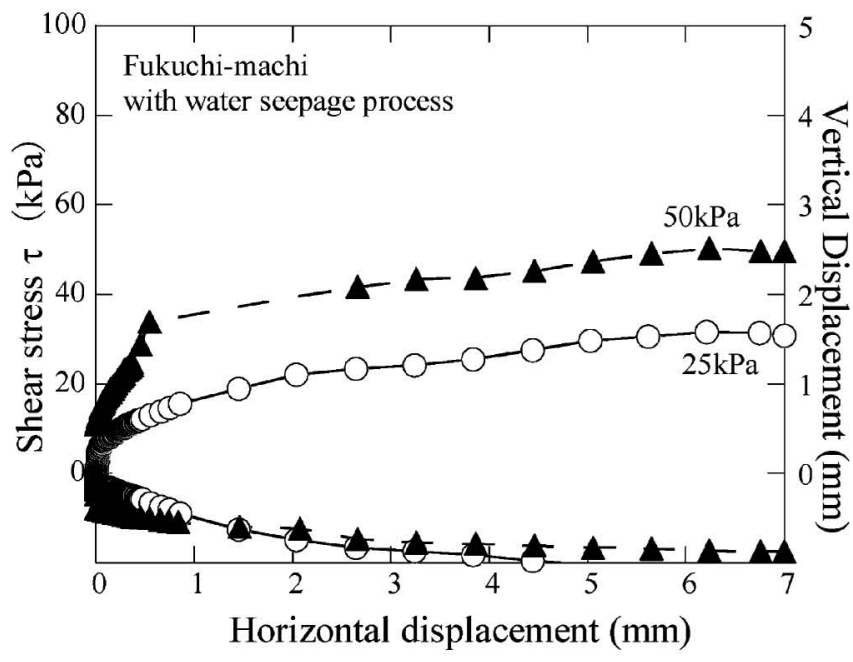

a) Fukuchi-machi were over 40 degrees, while the cohesions of Fukuchimachi and Takeda-city samples were $45.7 \mathrm{kPa}$ and 30.9 $\mathrm{kPa}$, respectively. The relatively high shear strength of the collapsed soil with the natural water content is relatively large, making it reasonable to suggest that collapsed slopes were originally stable enough not to be considered prone to slope failure. In order to examine the changes in the strength properties of collapsed soils due to water seepage of rainfall into the slopes, a series of consolidated constant pressure direct box shear tests was carried out for Fukuchi-machi and Sasaguri-machi samples with a water seepage process. In the water seepage process, the de-aired water was drained from the bottom of the specimen in the shear box for 30 minutes before the consolidation process. The consolidation pressures were $25 \mathrm{kPa}$ and $50 \mathrm{kPa}$. Figure 10 shows the shear stress and the vertical displacement against horizontal displacement for Fukuchi-machi and Sasaguri-machi specimens due to the water seepage process. Figure 11 shows the friction

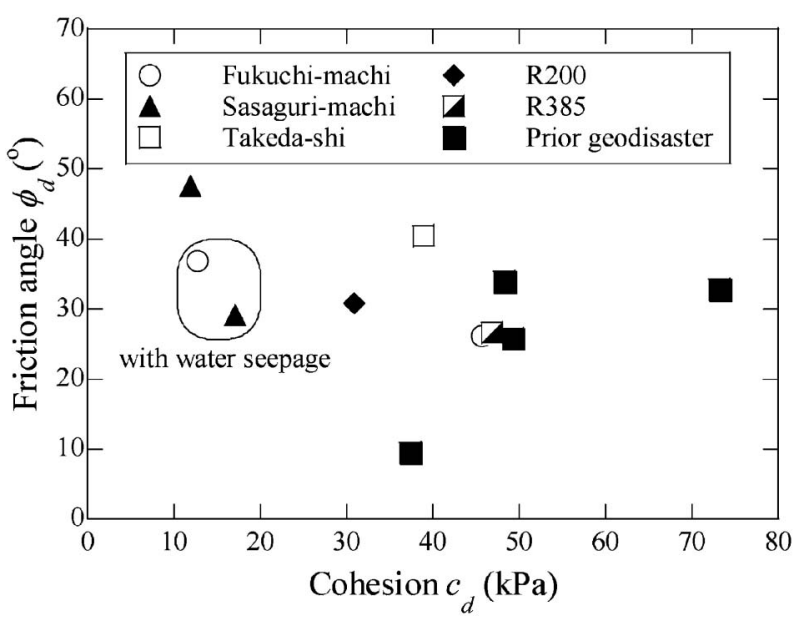

Fig. 11. Strength parameter of collapsed soils

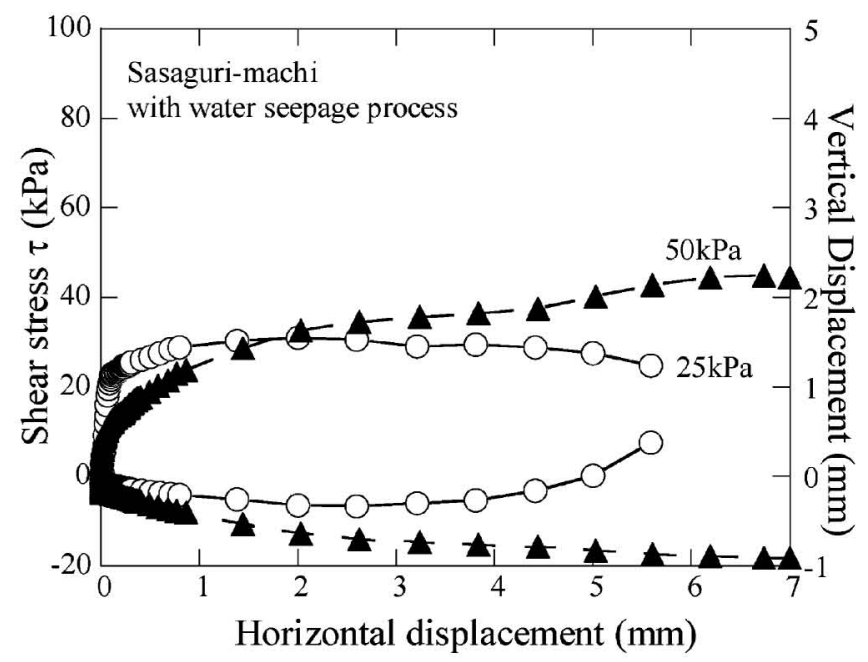

b) Sasaguri-machi

Fig. 10. Shear stress and vertical displacement against horizontal displacement under constant vertical stress with water seepage process 


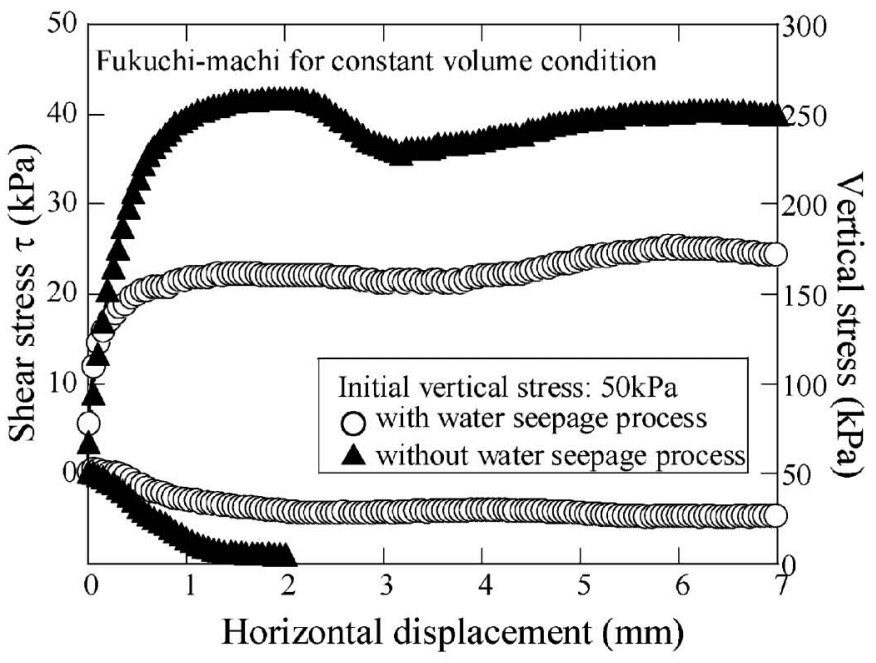

a) Fukuchi-machi

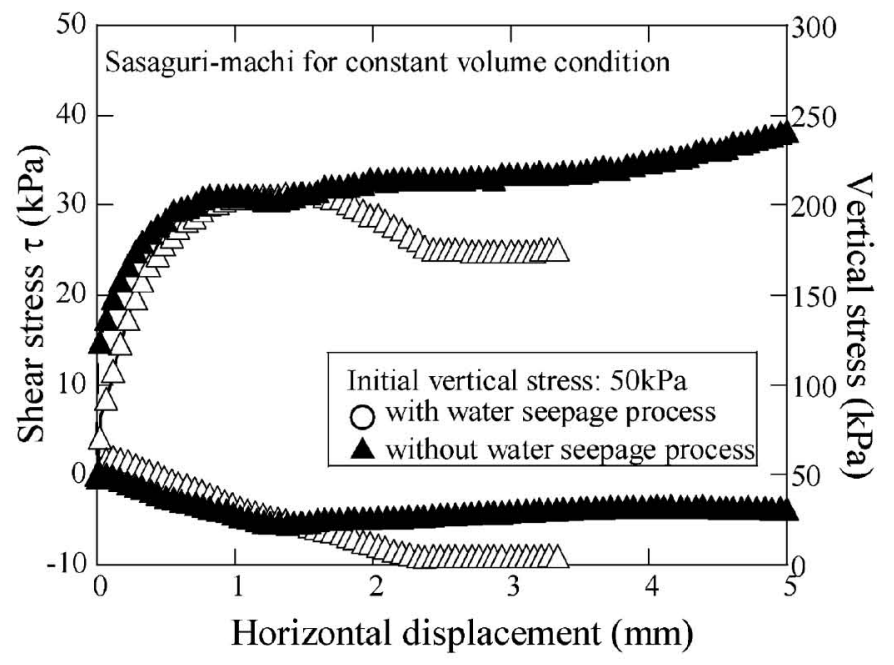

b) Sasaguri-machi

Fig. 12. Shear stress and vertical stress against horizontal displacement

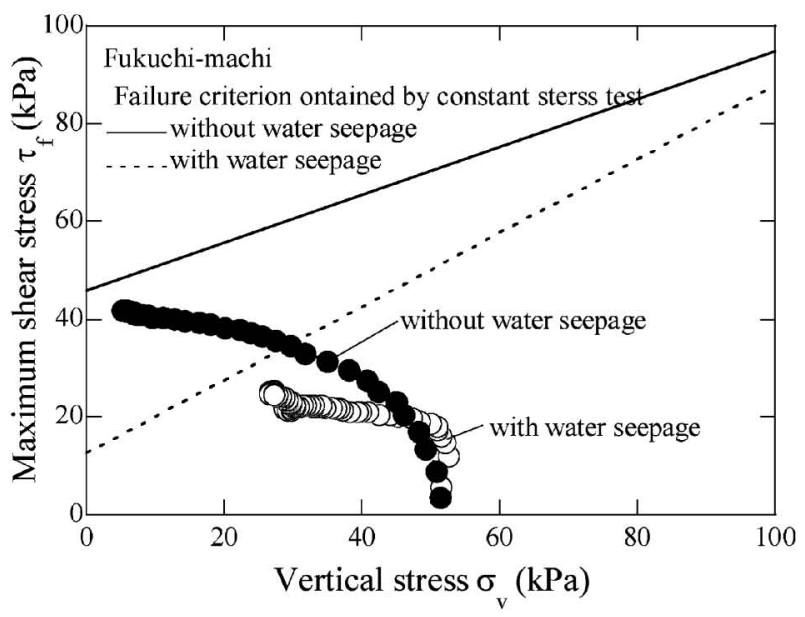

a) Fukuchi-machi

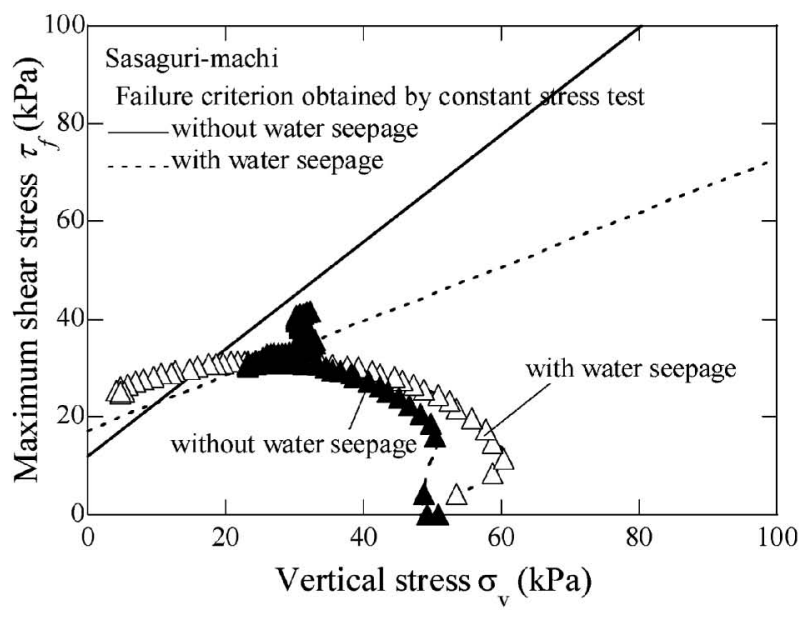

b) Sasaguri-machi

Fig. 13. Stress path under constant volume test

angle and cohesion for Fukuchi-machi and Sasagurimachi samples with/without the water seepage process together with the test results for the Takeda-shi, R200 and R385 specimens, as shown in Fig. 9. In addition, the test results for the collapsed soils taken from prior geodisaster sites in the Kyushu area (see the investigation report produced by Kyushu Branch of JGS, 2010) are also shown in the figure. The friction angle for the Fukuchi-machi specimen increases by about 10 degrees while the cohesion decreases by about $30 \%$. In the case of the Sasaguri-machi, the friction angle drastically decreases, by about $60 \%$. Consequently, the shear strength for any given initial vertical stress for Fukuchimachi and Sasaguri-machi specimens drastically decreases due to the decrease in cohesion (loss in suction) resulting from soil saturation cause by water seepage. The decrease in the strength parameter due to water seepage in this experiment, however, was shown to be de- pendent on the soil. Nevertheless, the decrease in soil resistance due to water seepage was well-established, and, therefore, it is clear that the seepage of rainfall into the slopes had a great influence on the stability of the slopes.

In order to evaluate the effect of the shear condition (constant pressure or constant volume condition) on the shear strength of collapsed soils, a series of consolidated constant volume direct box shear tests was carried out on the Fukuchi-machi and Sasaguri-machi specimens with/ without water seepage process. Specimens which had and had not been subjected to a water seepage process for 30 minutes were consolidated with a constant vertical pressure of $50 \mathrm{kPa}$ and then sheared with a constant volume condition (the undrained condition) up to $7 \mathrm{~mm}$ at a shear speed of $0.1 \mathrm{~mm} / \mathrm{min}$. Figure 12 shows the shear and vertical stresses against horizontal displacement. It can be seen that the shear stress and vertical stress for a given horizontal displacement decrease due to the water 
seepage process. Figure 13 shows the stress path with shear stress $\tau$ and the vertical stress $\sigma_{v}$ space together with the failure criteria obtained by consolidated constant pressure direct box shear tests for Fukuchi-machi and Sasaguri-machi specimens, as shown in Fig. 9. It can be seen that shear stress increases with decreasing vertical stress similar to normally consolidated clay. It can be seen that there is a unique failure criterion irrespective of the difference in constant pressure (the drained condition) or constant volume (the undrained condition), which is a common understanding in conventional soil mechanics, based on the experimentally esablished fact that the stress

Table 8. Shear strength, saturation and test conditions for Fukuchimachi and Sasaguri-machi samples

\begin{tabular}{|c|c|c|c|c|c|}
\hline Soil sample & $\begin{array}{l}\text { Drain } \\
\text { condition }\end{array}$ & $\begin{array}{c}\text { Water } \\
\text { seepage }\end{array}$ & $\begin{array}{c}\text { Saturation } \\
(\%)\end{array}$ & $\begin{array}{l}\text { Vertical } \\
\text { stress } \\
(\mathrm{kPa})\end{array}$ & $\begin{array}{c}\text { Shear } \\
\text { strength } \\
(\mathrm{kPa})\end{array}$ \\
\hline \multirow{7}{*}{ Fukuchi-machi } & \multirow{5}{*}{$\begin{array}{l}\text { Constant } \\
\text { stress }\end{array}$} & \multirow{3}{*}{ No } & 84.9 & 25 & 55.2 \\
\hline & & & 87.8 & 50 & 75.7 \\
\hline & & & 96.7 & 75 & 79.7 \\
\hline & & \multirow{2}{*}{ Yes } & 81.3 & 25 & 31.5 \\
\hline & & & 87.2 & 50 & 50.3 \\
\hline & \multirow{2}{*}{$\begin{array}{l}\text { Constant } \\
\text { volume }\end{array}$} & No & 87.9 & 50 & 41.8 \\
\hline & & Yes & 91.0 & 50 & 25.4 \\
\hline \multirow{7}{*}{ Sasaguri-machi } & \multirow{5}{*}{$\begin{array}{l}\text { Constant } \\
\text { stress }\end{array}$} & \multirow{3}{*}{ No } & 62.5 & 25 & 36.4 \\
\hline & & & 68.8 & 50 & 72.6 \\
\hline & & & 68.0 & 75 & 91.2 \\
\hline & & \multirow{2}{*}{ Yes } & 91.4 & 25 & 31.0 \\
\hline & & & 83.0 & 50 & 44.9 \\
\hline & \multirow{2}{*}{$\begin{array}{l}\text { Constant } \\
\text { volume }\end{array}$} & No & 66.3 & 50 & 41.6 \\
\hline & & Yes & 90.3 & 50 & 31.3 \\
\hline
\end{tabular}

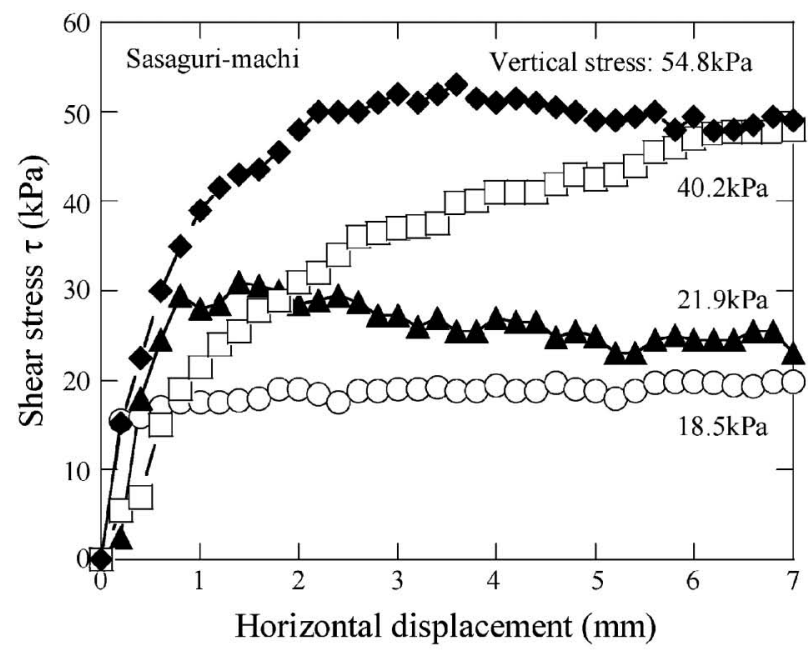

a) Shear stress and horizontal displacement path under the constant volume condition finally approaches the failure criteria obtained by the constant pressure direct box shear test. Comparison with the shear strength for any given vertical stress in terms of the constant pressure and constant volume conditions, however, show that the shear strength under the constant pressure condition was larger than that under constant volume condition. The shear strength, saturation and test conditions for Fukuchi-machi and Sasaguri-machi samples are summarized in Table 8.

In order to evaluate the effects of water seepage and the shear condition on the decrease in the shear strength of the collapsed soils, the rate of decrease in the shear strength is summarized in Table 9. It should be noted that the rate of decrease was normalized by the shear strength obtained under the constant pressure condition without the water seepage process. Moreover, the results of the permeability test are also shown in the table. Shear strength under the constant pressure condition for the Fukuchi-machi specimen decreases by $57.1 \%$ to $66.4 \%$ due to water seepage. In the case of the Sasaguri-machi specimen, the decrease in shear strength in the absence of he water seepage process under constant pressure was

Table 9. Shear strength reduction due to water seepage and the drain condition in shear process

\begin{tabular}{|c|c|c|c|c|}
\hline Soil sample & $\begin{array}{c}\text { Drain } \\
\text { condition }\end{array}$ & $\begin{array}{l}\text { Vertical } \\
\text { stress } \\
(\mathrm{kPa})\end{array}$ & $\begin{array}{l}\text { Shear strength } \\
\text { reduction } \\
(\%)\end{array}$ & $\begin{array}{l}\text { Saturated } \\
\text { permeability } \\
(\mathrm{cm} / \mathrm{sec})\end{array}$ \\
\hline \multirow{2}{*}{ Fukuchi-machi } & $\begin{array}{l}\text { Constant } \\
\text { stress }\end{array}$ & $\begin{array}{l}25 \\
50\end{array}$ & $\begin{array}{l}57.1 \\
66.4 \\
\end{array}$ & \multirow{2}{*}{$2.66 \times 10^{-3}$} \\
\hline & $\begin{array}{l}\text { Constant } \\
\text { volume }\end{array}$ & 50 & 33.5 & \\
\hline \multirow{2}{*}{ Sasaguri-machi } & $\begin{array}{l}\text { Constant } \\
\text { stress }\end{array}$ & $\begin{array}{l}25 \\
50\end{array}$ & $\begin{array}{l}85.2 \\
61.8\end{array}$ & \multirow{2}{*}{$9.64 \times 10^{-7}$} \\
\hline & $\begin{array}{l}\text { Constant } \\
\text { volume }\end{array}$ & 50 & 43.1 & \\
\hline
\end{tabular}

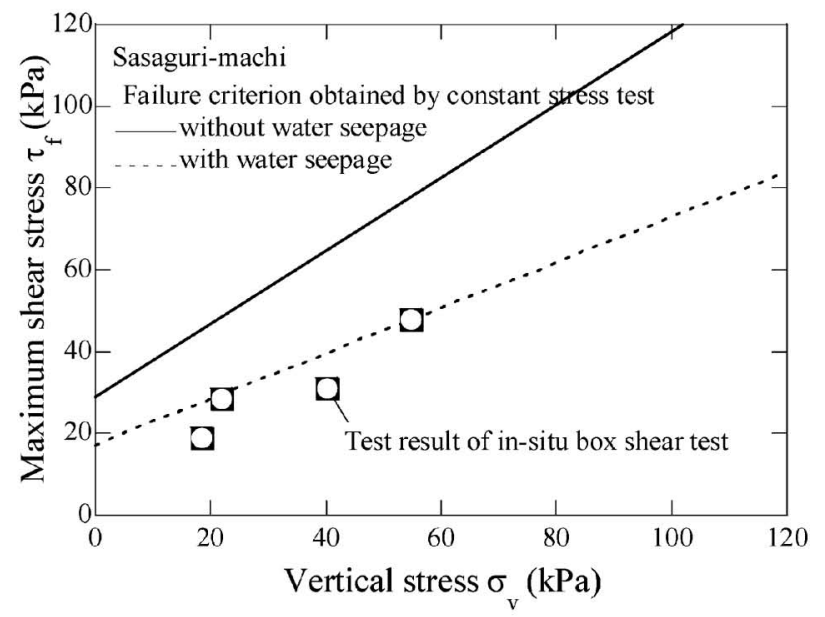

b) Failure criterion

Fig. 14. Test results of in-situ box shear test 
$61.8 \%-85.2 \%$. Moreover, both the water seepage and constant volume shear condition cause a reduction of about 30\%-40\% in shear strength for the Fukuchi-machi and Sasaguri-machi samples. As the saturated permeability of Sasaguri-machi sample, at $9.64 * 10^{-7} \mathrm{~cm} / \mathrm{sec}$, is relatively low, and this is also to the case for clayey soils, it is expected that the extent of the strength reduction was remarkable for the Sasaguri-machi soil.

\section{Field Application of In-situ Box Shear Test}

In addition to a series of direct box shear tests, an insitu shear test was carried out on the slope failure at Sasaguri-machi in order to examine the applicability of the in-situ shear test for estimating the in-situ shear strength at the field. The test apparatus for the simplified in-situ box shear test used in this investigation was originally developed by Yamamoto et al. (2001). The specimen for this test apparatus is $60 \mathrm{~mm}$ in diameter and 20 $\mathrm{mm}$ in height, and is trimmed and shaped from the original slope by hand. The vertical stress of the specimen depends on the amount of pressure applied by the human sample-taker. Figure 14(a) shows the shear stress against horizontal displacement obtained by the in-situ box shear test. It can be seen that there is a monotonic increase in shear stress with horizontal displacement, indicating that the in-situ soil is in a loose condition and the maximum shear stress increases as the vertical stress increases. Figure 14(b) compares the failure criteria for the Sasaguri-machi slope obtained by the in-situ box shear test and the consolidated constant pressure direct box shear test with/without the water seepage process. The test results of the in-situ box shear test are close to the failure criteria with the water seepage process. Further investigation is required to evaluate the applicability of the simplified in-situ box shear test.

\section{GEO- AND HYDRO- MECHANICAL EVELUATION OF GEODISASTER}

In order to investigate the generation mechanism of slope failure followed by debris flow due to rainfall, a slope deformation and stability analysis coupling unsaturated-saturated seepage analysis was conducted by a finite difference approach (FLAC, Itasca Corporation) for the collapsed slope at Fukuchi-machi based on the geotechnical investigation mentioned above.

The formulation of the coupled fluid-deformation mechanisms in FLAC is based on the Biot theory of consolidation. The governing differential equations are discussed below.

\section{1) Transport Law}

The fluid transport is described by Darcy's law:

$$
q_{\mathrm{i}}=-k_{\mathrm{ij}} \hat{k}(s) \frac{\partial}{\partial x_{\mathrm{j}}}\left(P-\rho_{\mathrm{w}} g_{\mathrm{k}} x_{\mathrm{k}}\right)
$$

where $q_{\mathrm{i}}$ is the specific discharge vector, $k_{\mathrm{ij}}$ is the mobility coefficient (FLAC's permeability tensor), $\hat{k}(s)$ is the relative permeability, which is a function of the saturation $s$,
$P$ is the fluid pressure, $\rho_{\mathrm{w}}$ is the mass density of the fluid, and $g_{\mathrm{i}}, i=1,2$ are the two components of the gravity vector. For saturated/unsaturated flow, the air pressure is assumed to be constant and equal to zero.

\section{2) Balance Laws}

The fluid mass balance relation is

$$
\frac{\partial \zeta}{\partial t}=-\frac{\partial q_{\mathrm{i}}}{\partial x_{\mathrm{i}}}+q_{\mathrm{v}}
$$

where $\zeta$ is the variation of fluid content (variation of fluid volume per unit volume of porous material), and $q_{\mathrm{v}}$ is the volumetric fluid source intensity.

\section{3) Constitutive Laws}

The response equation for the pore fluid depends on the value of the saturation. At full saturation, $s=1$, the response equation is

$$
\frac{\partial P}{\partial t}=M\left(\frac{\partial \zeta}{\partial t}-\alpha \frac{\partial \varepsilon}{\partial t}\right)
$$

where $P$ is the fluid pressure, $M$ is Biot modulus, $\alpha$ is Biot coefficient and $\varepsilon$ is the volumetric strain. Biot modulus is related to the drained bulk modulus of the porous medium, $K$, and the fluid bulk modulus, $K_{\mathrm{w}}$. More references are listed in Section 1 of FLAC Ver. 5 (Fluid-Mechanical Interaction).

\section{Fluid Flow Boundary and Initial Conditions}

Four different types of boundary conditions are imposed in FLAC: (1) constant pore pressure; (2) constant specific discharge; (3) leaky boundaries; and (4) impermeable boundaries (default condition). A leaky boundary condition has the form

$$
q_{\mathrm{n}}=h\left(p-p_{\mathrm{e}}\right)
$$

where $q_{\mathrm{n}}$ is the component of the specific discharge normal to the boundary in the direction of the exterior normal, $h$ is the leakage coefficient-e.g., in $\left[\mathrm{m}^{3} / \mathrm{N}-\mathrm{sec}\right], p$ is the pore pressure calculated at the boundary surface, and $p_{\mathrm{e}}$ is the known pore pressure in the region to or from which leakage is assumed to occur. Additional boundary conditions, such as a given total influx over a uniform pressure boundary segment, can be imposed using FISH in FLAC.

Flow may take place in a zone even when all nodal pressures are zero. In this case, gravity may cause fluid to migrate through a zone that is not fully saturated. However, there are two factors to consider: (a) the apparent permeability should decrease as the saturation decreases -in particular, permeability should be zero for zero saturation; and (b) fluid cannot be extracted from a node of zero saturation.

To address point (a), the flow rates (and thereby the apparent permeability) are multiplied by a factor, $\hat{k}$, that depends on saturation, $s$ :

$$
\hat{k}(\mathrm{~s})=s^{2}(3-2 s)
$$

This function is empirical but has the property the, $\hat{k}=0$ 


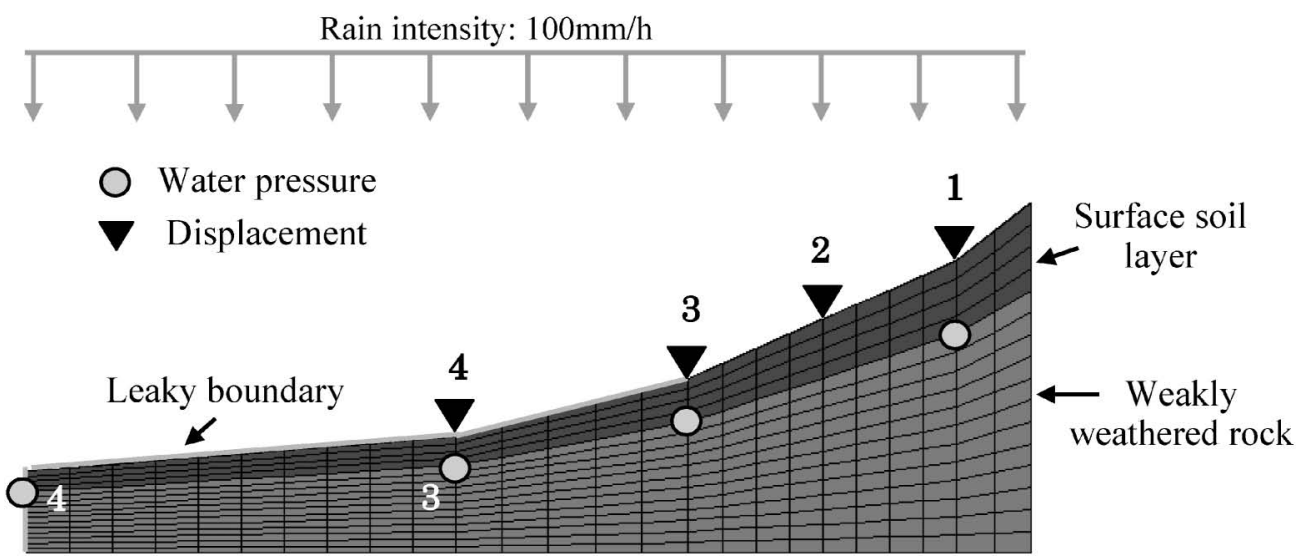

Fig. 15. Finite element mesh and boundary condition

Table 10. Input parameters for numerical analysis

\begin{tabular}{l|c|c}
\hline & Surface soil layer & Weakly weathered rock \\
\hline Permeability $k_{\mathrm{h}}(\mathrm{cm} / \mathrm{sec})$ & $5.0^{*} 10^{-3}$ & $5.0^{*} 10^{-5}$ \\
\hline Porosity $n$ & 0.2 & 0.2 \\
\hline Elastic modulus $E(\mathrm{MPa})$ & 200 & 300 \\
\hline Poisson's Ratio $v$ & 0.3 & 0.13 \\
\hline Density $\rho\left(\mathrm{Mg} / \mathrm{m}^{3}\right)$ & 1.7 & 2.3 \\
\hline Cohesion $c(\mathrm{kPa})$ & 10 & - \\
\hline Friction angle $\phi(\mathrm{deg})$ & 30 & - \\
\hline
\end{tabular}

if $s=0$, and $\hat{k}=1$ if $s=1$; i.e., permeability is unchanged for full saturation, and is zero for zero saturation. Further, the gradient of the equation is zero at $s=0$ and $s=1$, which is reasonable to expect physically.

Figure 15 shows a finite element mesh used to simulate the collapsed slope at Fukuchi-machi as shown in Fig. 5. The bed rock and surface soil layer were modeled as elastic material and elasto-plastic material, respectively. The problem is two dimensional. The mechanical boundary conditions correspond to the roller boundary at the right side and the fixed boundary at the bottom of the model. The layer in the model is elastic, the porosity, $n$, is uniform with a value of 0.2 . In this study, the intensity of precipitation was assumed to be $100 \mathrm{~mm} / \mathrm{h}$ and applied at the nodes on the slope surface by defining the values of raining pressures based on the observatory record as shown in Fig. 3 and Table 4 . The bottom and the right side of the model are assumed as the non fluid-flow boundary conditions. The input parameters, such as strength parameter and permeability, were determined based on the laboratory tests in the prior section and are summarized in Table 10. Based on the experimental results showing that the cohesion and friction angle for Fukuchi-machi sample after water seepage process are $12.7 \mathrm{kPa}$ and $36.9^{\circ}$ respectively, the input cohesion and friction angle were roughly assumed to be $10 \mathrm{kPa}$ and $30^{\circ}$ respectively. In this study, the strength parameters, such as cohesion and the friction angle, were assumed to be constant for simplicity although there was strength dependency on the soil saturation, as shown in Table 8 . Input permeability was selected to be $5^{*} 10^{-3} \mathrm{~cm} / \mathrm{sec}$ in a similar order to the experimentally obtained permeability for the Fukuchi-machi sample, at $2.66^{*} 10^{-3} \mathrm{~cm} / \mathrm{sec}$. The two soil layers were initially in the unsaturated condition.

Figure 16 shows the distribution of pore water pressure and the vector of water seepage in the slope after 4, 8, 12 and 16 hours. The vertical seepage in the surface soil layer was remarkable for first 4 hours, and then downward seepage parallel to slope occurred. In addition, the pore water pressure of the surface soil layer accumulated from the lower part to the upper part of the slope as time elapsed.

In order to examine the timing of slope failure after the rain started, Fig. 17 shows the maximum unbalanced force ratio against the elapsed time obtained by the stability analysis. The term "unbalanced force ratio" refers to the ratio of driving force and soil resistance for the soil element. The magnitude of maximum unbalanced force ratio was shown to have increased sharply at 12 hours, indicating that large slope deformation occurred at this moment. Figure 18 shows a deformed mesh, with distributions of horizontal displacement and shear strain in the slope at 12 hours. Considerable deformation was observed in the surface soil mesh near the top of slope and shear strain was generated in surface soil layer, which indicate that shallow slope failure occurred and triggered a debris flow. It can be confirmed that torrential rainfall induced large pore water pressure near the top of slope despite the low slope angle, and this was an influential factor, triggering slope failure followed by debris flow. In order to examine the detailed mechanism of the slope failure, however, the mesh near slope surface needs to be refined and the effect of the boundary conditions, such as the leaky boundary just below the slope failure, need to be clarified. This needs to be done in order to properly characterise the soil-water characteristics and the nonlinear response of the soil. 


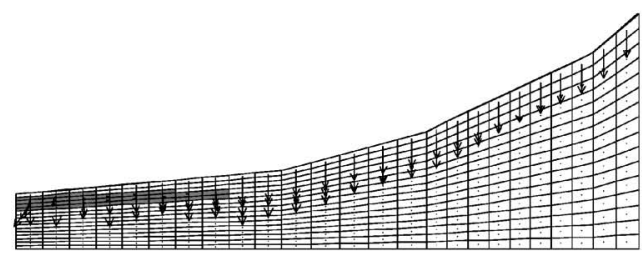

a) 4 hours

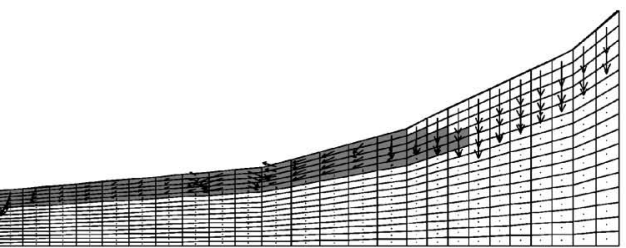

b) 8 hours

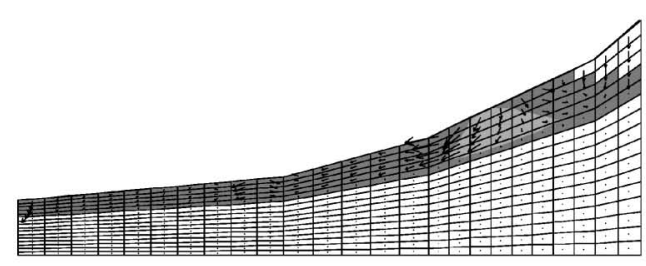

c) 12 hours

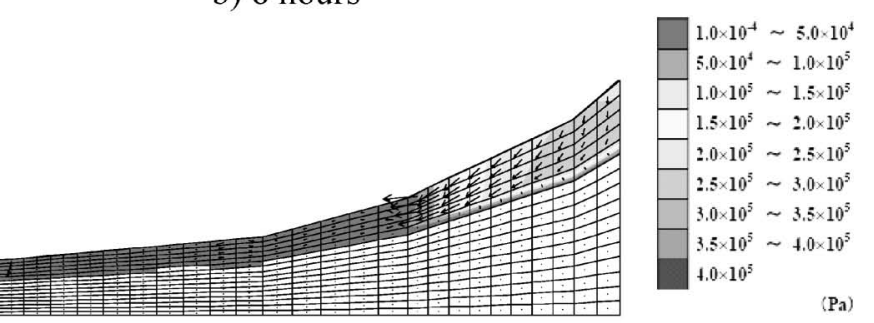

d) 16 hours

Fig. 16. The distribution of water pressure obtained by seepage analysis

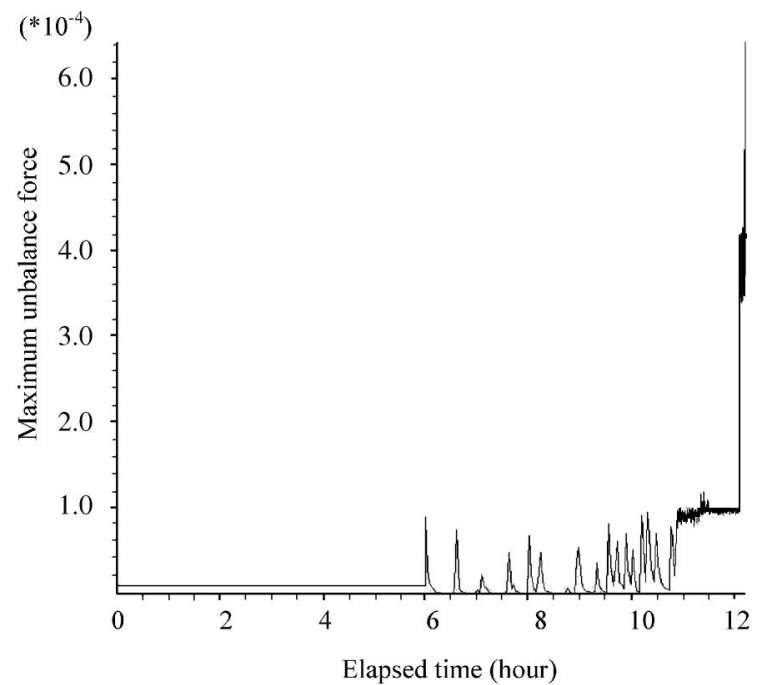

Fig. 17. Maximum unbalance force against elapsed time

\section{CONCLUSIONS}

This paper summarizes the results of the geotechnical investigations on the geodisaster sites in Fukuoka prefecture. The geotechnical investigation included a series of grain size distributions, consistency limits and direct box shear tests for collapsed soils collected at six disaster sites. The generation mechanisms of slope failure followed by debris flow were also investigated by analyzing precipitation, topography, geology, and the strength properties of the collapsed soils. In addition, slope deformation and stability analyses were coupled with an unsaturated-saturated seepage analysis to investigate the slope failure mechanism.

The main findings from the study can be summarized as follows:

The physical properties, such as the grain size distribution, the plastic limit and the liquid limit of the collapsed soils, were compared with results from other failure slopes in the literature. The collapsed soil had the follow-

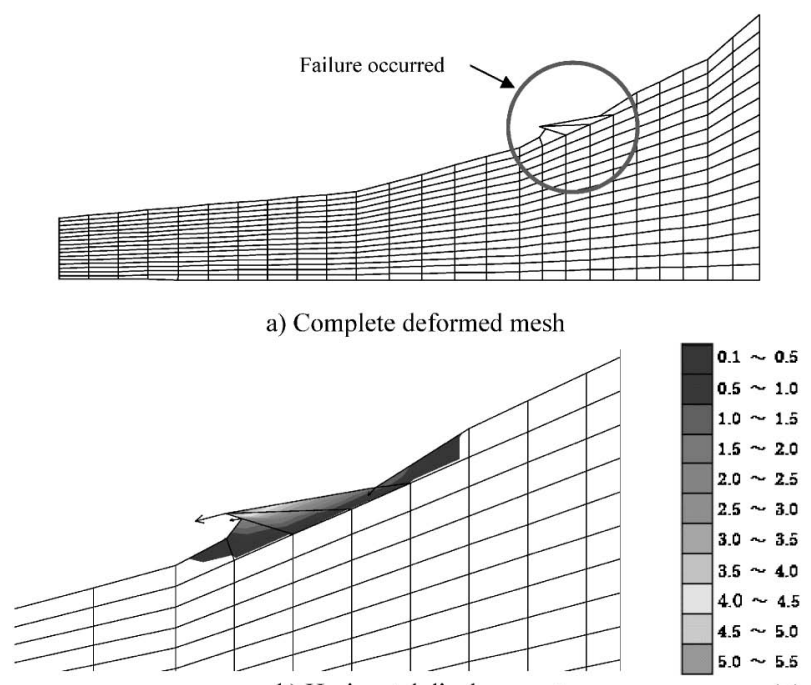

b) Horizontal displacement $(\mathrm{m})$

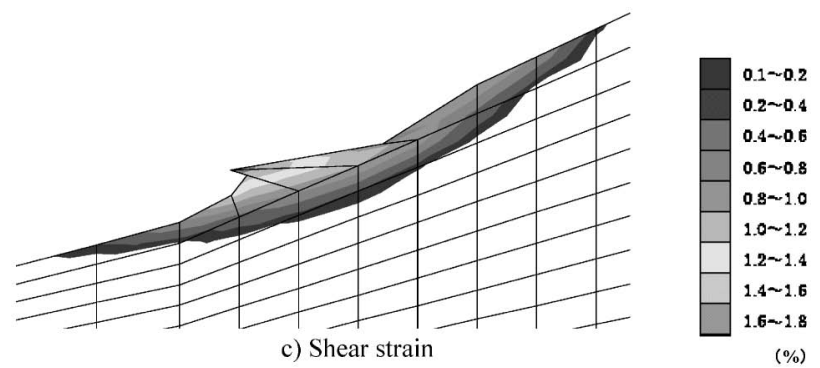

Fig. 18. The results of stability analysis

ing characteristics: the soil was well grained (the uniformity coefficient $>50$ ) and highly weathered (the ignition loss $>5 \%$ ). There was no obvious feature of the collapsed soils in terms of their liquid limit and plasticity index.

The original shear strength of the collapsed soils with natural water content was large enough that slope failure would not occur since the cohesion in shear strength was induced by suction under the unsaturated condition. However, water seepage into the soil induced a drastic 
decrease in the shear strength, mainly caused by a decrease in cohesion (loss of suction) resulting from soil saturation. In addition, the drained/undrained condition under the shear process is also sensitive to shear strength. For example, both water seepage and the shear process with constant volume resulted in about a $30 \%$ to $40 \%$ reduction in shear strength for the Fukuchi-machi and Sasaguri-machi soil samples. The reduction of cohesive strength due to water seepage and low permeability of the slope were thus shown to be influential parameters to trigger geodisaster.

Based on the results of the slope deformation and stability analyses to simulate geodisaster at Fukuchi-machi, which took changes in the water pressure and cohesive strength into account, it is expected that shallow failure near the top of the slope occurred due to torrential precipitation about $100 \mathrm{~mm}$ per hour, which triggered debris flow.

\section{ACKNOWLEDGEMENT}

A series of site investigations and geotechnical tests for the collapsed soils was done with the cooperation of the Kyushu branch of the Japanese Geotechnical Society. A grateful acknowledgement is made to Professor Hidetoshi Ochiai, Professor Kouki Zen, Associate Professor Guangqi Chen, and Associate Professor Kiyoshi Omine of Kyushu University for their helpful advice and encouragement. The authors wish to express their sincere appreciation to Yuichi Yahiro and Kazuo Kishimoto, a technician and graduate student of Kyushu University, for their cooperation in carrying out the laboratory tests.

\section{REFERENCES}

1) Kasama, K., Zen, K. and Chen, G. (2006): Test results of box shear test for pumice fall deposits (Bora) in Kagoshima, Western Regional Division Report of Natural Disaster Research Council, 30, 81-82 (in Japanese).

2) Kyushu Branch of the Japanese Geotechnical Society (2003): Investigation Report on Geodisaster in Kyushu Island Caused by Rain Front, July 2003, (in Japanese).

3) Kyushu Branch of the Japanese Geotechnical Society (2009): Prompt report on casualties and damage after the great 2008 Sichuan Earthquake, Western Regional Division Report of Natural Disaster Research Council, 33, 83-150 (in Japanese).

4) Kyushu Branch of the Japanese Geotechnical Society (2010): Investigation Report on Geodisaster in Northern-Kyushu area Induced by Torrential Rains, July 2009, (in Japanese).

5) Yahiro, Y., Zen, K., Chen, G. and Kasama, K. (2006): Report for geotechnical disaster in Oita caused by typhoon No. 14 in 2005, Western Regional Division Report of Natural Disaster Research Council, 30, 57-60 (in Japanese).

6) Yahiro, Y., Zen, K., Chen, G. and Kasama, K. (2007): Report for geotechnical disaster in Saga caused by typhoon No. 13 in 2006, Western Regional Division Report of Natural Disaster Research Council, 31, 35-38 (in Japanese).

7) Yamamoto, T., Suzuki, M., Terayama, T. and Harada, H. (2001): Evaluation of shear strength along discontinuous planes causing slope failures, Tsuchi-to-Kiso, 49(7), Ser. No. 522, 7-9 (in Japanese). 